\title{
Clinical utilization of anti-vascular endothelial growth-factor agents and patient monitoring in retinal vein occlusion and diabetic macular edema
}

This article was published in the following Dove Press journal:

Clinical Ophthalmology

26 August 2014

Number of times this article has been viewed

\author{
Szilárd Kiss' \\ Ying Liu ${ }^{2}$ \\ Joseph Brown ${ }^{3}$ \\ Nancy M Holekamp ${ }^{4,5}$ \\ Arghavan Almony ${ }^{6}$ \\ Joanna Campbell ${ }^{2}$ \\ Jonathan W Kowalski \\ 'Weill Cornell Medical College, New \\ York, NY; ${ }^{2}$ Allergan, Inc., Irvine, CA; \\ ${ }^{3}$ IMS Health, Woodland Hills, CA; \\ ${ }^{4}$ Pepose Vision Institute, Chesterfield, \\ MO; ${ }^{5}$ Washington University School of \\ Medicine, St Louis, MO; ${ }^{6}$ Carolina Eye \\ Associates, Southern Pines, NC, USA
}

Correspondence: Szilárd Kiss Weill Cornell Medical College New York Presbyterian Hospital, I305 York Avenue - I I th Floor, New York, NY 10021 , USA

Tel +16469622217

Fax +I 6469620609

Emailszk700I@med.cornell.edu
Purpose: To examine the utilization of bevacizumab and ranibizumab and disease monitoring in patients with branch or central retinal vein occlusion (BRVO/CRVO) or diabetic macular edema (DME) in clinical practice.

Patients and methods: This retrospective claims analysis included newly diagnosed patients with one or more bevacizumab or ranibizumab injections. Bevacizumab or ranibizumab utilization was assessed by year of first injection: 2008-2010 cohorts (12-month follow-up), January to June 2011 cohort (6-month follow-up). The main outcome measures were mean annual numbers of injections, ophthalmologist visits and optical coherence tomography examinations, and proportion of patients with additional laser or intravitreal triamcinolone (IVTA) use.

Results: A total of 885 BRVO, 611 CRVO, and 2,733 DME patients treated with bevacizumab were included, with too few ranibizumab-treated patients for meaningful analysis. Across the 2008, 2009, and 2010 cohorts, mean annual numbers of bevacizumab injections increased, but remained low (BRVO 2.5, 3.1, 3.3; CRVO 3.1, 3.1, 3.5; and DME 2.2, 2.5, 3.6, respectively); mean ophthalmologist visits ranged between 4.4 and 6.5 , and mean optical coherence tomography examinations ranged between 3.1 and 3.9 across all conditions. A total of $42.0 \%$ of BRVO, $16.5 \%$ of CRVO, and $57.7 \%$ of DME patients received additional laser or IVTA therapy. The number of bevacizumab injections was positively associated with laser use in BRVO (3.3 versus $2.9, P<0.03$ ), and with laser or IVTA use in DME (laser, 3.3 versus 2.7, $P<0.03$; IVTA, 3.3 versus 3.0, $P<0.05$ ).

Conclusion: During the study period (2008-2011), bevacizumab was the main anti-VEGF therapy used in clinical practice for BRVO, CRVO, and DME. Patients treated with bevacizumab were monitored less frequently and received fewer injections than patients in major clinical trials of ranibizumab.

Keywords: anti-vascular endothelial growth factor, bevacizumab, ranibizumab, diabetic macular edema, retinal vein occlusion, intravitreal

\section{Introduction}

Retinal vein occlusion (RVO), divided into central (CRVO) or branch (BRVO), and diabetic macular edema (DME) are among the most common retinal vascular diseases responsible for vision loss and blindness. ${ }^{1-4}$ RVO and DME are estimated to affect approximately 16.4 million and 21 million people worldwide, respectively. ${ }^{5,6}$ Although the pathogeneses of CRVO, BRVO, and DME are multifactorial, upregulation of VEGF is a common underlying source of vision loss in all three diseases..$^{7-10}$

Treatment options for patients with macular edema secondary to BRVO, CRVO, or DME include laser surgery, intravitreal corticosteroids, and intravitreal antiVEGF agents. Anti-VEGF agents, including ranibizumab (Lucentis ${ }^{\circledR}$; Genentech, 
San Francisco, CA, USA) and bevacizumab (Avastin ${ }^{\circledR}$; Genentech), have become standard therapy in these conditions. Ranibizumab was initially approved in the US for the treatment of neovascular (wet) age-related macular degeneration (nAMD) in 2006; it received approvals for BRVO and CRVO in June 2010, and for DME in August 2012. Bevacizumab is not US Food and Drug Administration-approved for intraocular use, but is widely used off-label for all four indications. A third agent, aflibercept (Eylea ${ }^{\circledR}$; Regeneron Pharmaceuticals, Inc., Tarrytown, NY, USA) was approved for CRVO in September 2012 and is currently under regulatory evaluation for DME.

Since 2009, major Phase II and III trials have demonstrated that the use of ranibizumab, either alone or in conjunction with laser photocoagulation, is associated with significant improvement in visual acuity in BRVO, CRVO, and DME when compared with observation (BRVO and CRVO) or laser therapy (DME). ${ }^{1-18}$ Although these studies differ in baseline-population characteristics, as a whole they suggest a trend toward greater visual benefit associated with more frequent injections. In DME, studies utilizing more frequent injection regimens (RESOLVE ${ }^{12}$ and RISE/RIDE ${ }^{15}$ ) have resulted in a greater mean number of letters gained over 12 months than studies adopting less frequent injection regimens (RESTORE ${ }^{13}$ and the Diabetic Retinopathy Clinical Research Network [DRCR.net] Protocol I ${ }^{17,18}$ ), despite all following a monthly follow-up schedule. In BRVO and CRVO, where fewer pivotal trials of anti-VEGF agents have been conducted, a similar trend was observed when comparing the pivotal trials BRAVO in BRVO ${ }^{11}$ and CRUISE in CRVO,${ }^{14}$ using monthly injections and monitoring visits in the initial 6 months with their extension phases (including the second 6-month "as-needed" phase of BRAVO and CRUISE, as well as HORIZON ${ }^{16}$ ), which employed considerably fewer injections and monitoring visits. This trend is also consistent with that observed in pivotal studies of nAMD, where there is both direct evidence (2-year $\mathrm{CATT}^{19}$ ) and indirect evidence (comparison of ANCHOR, ${ }^{20}$ MARINA, ${ }^{21} 1$-year CATT, ${ }^{22}$ IVAN, ${ }^{23}$ and HARBOR ${ }^{24}$ studies) to suggest that monthly follow-up and frequent ranibizumab or bevacizumab injections are required to achieve optimal visual improvement.

Relatively little is known about the use of bevacizumab and ranibizumab in BRVO, CRVO, and DME in clinical practice, which began on an off-label basis as early as 2006 . It is also unclear whether the publication of major randomized clinical trials since late 2009 has had any impact on the use of these two agents in clinical practice. Furthermore, there is limited information about the prevalence of focal/grid laser photocoagulation and/or corticosteroid therapies among patients treated with anti-VEGF agents in these conditions. This study addresses these issues using one of the largest fully integrated claims databases in the US. The study period (2008-2011) starts approximately 1 year before the findings of the pivotal ranibizumab BRVO (BRAVO) ${ }^{11}$ and CRVO (CRUISE) $^{14}$ trials were first presented at the 2009 Annual Meeting of the American Academy of Ophthalmology, and ends about 1 year after the publication of Phase III ranibizumab DME studies in 2010 (RESTORE and Protocol I). ${ }^{13,17,18}$

\section{Patients and methods Data source}

This retrospective analysis used claims data from 2008-2011 from the IMS LifeLink ${ }^{\mathrm{TM}}$ health plan claims database, a fully integrated insurance database covering some 64 million unique patients from approximately 80 health plans across the US. This database consists primarily (about 70\%) of a commercially insured population, with the remaining 30\% being self-insured, on Medicaid, or Medicare managed care patients. The commercial population in the IMS LifeLink database comprises patients covered under an employersponsored private health plan, regardless of age; accordingly, it also includes retirees with supplemental insurance through their former employer. The Medicare patients in the database are represented by Medicare risk plans (mostly health maintenance organization [HMO] plans, in which the patient pays a flat fee to a Medicare risk contractor) and Medicare cost (Medigap) plans (a mixture of HMO and nonHMO plans, in which the patient purchases supplemental Medicare insurance). No personal identifying information was available in the database, and this study did not require human patient review.

\section{Inclusion/exclusion criteria}

To ensure the inclusion of newly diagnosed and anti-VEGF treatment-naïve patients, the analysis sample consisted of individuals who: 1) had a first diagnosis (index diagnosis) of DME (International Classification of Diseases [ICD]-9 codes of $362.07,362.83$, or 362.53 with a diagnosis of diabetes [250.xx] reported within the preceding 365 days, as based on previous studies), ${ }^{25,26}$ BRVO (ICD-9 code of 362.36), or CRVO (ICD-9 code of 362.35) in January 2007 or later; 2) had no same diagnosis in the 12 months before the index diagnosis; 3 ) received the first bevacizumab or ranibizumab injection (index date) between January 
2008 and June 2011 and within 12 months of the index diagnosis; 4) did not receive bevacizumab or ranibizumab injections before the index diagnosis; 5) were continuously enrolled from at least 12 months before the index diagnosis through 12 months after the index date; and 6) were 18 years of age or older at the time of the index date. Patients were assigned to distinct cohorts according to the anti-VEGF agent received (bevacizumab or ranibizumab) and year of first injection: 2008, 2009, and 2010 cohorts with 12 months' follow-up available, and January to June 2011 cohort with 6 months' follow-up available. To maximize internal validity, the study excluded patients with diagnoses of more than one of the retinal diseases that are commonly treated with anti-VEGF agents (ie, BRVO, CRVO, DME, and nAMD [ICD-9 codes 362.42, 362.43, or 362.52, and those with an ICD-9 code of 362.50 listed on the same claim with an intravitreal injection]) and those who were treated with both bevacizumab and ranibizumab.

\section{Health care resource utilization identification}

Anti-VEGF injections were identified using Healthcare Common Procedure Coding System (HCPCS) J codes (bevacizumab, J3490 [2008 onward], J3590 [2008 onward], J9035, Q2024 [fourth quarter of 2009 only], and C9257 [2010 onward]; ranibizumab, J2778 [2008 onward] and C9233 [2007 only]). Similarly, intravitreal triamcinolone (IVTA) was identified by HCPCS codes J3300, J3301, J3302, and J3303. Laser treatment and diagnostic tests for the index diagnosis were identified by Current Procedural Terminology (CPT) codes (laser, 67210 and 67220; optical coherence tomography [OCT] examinations, 92135 [until June 2011] and 92134 [January 2011 onward]; and fluorescein angiography [FA] examinations, 92235). Anti-VEGF and IVTA injections were both required to have the index diagnosis on the same claim or an intravitreal injection (CPT 67028) on the same date. All treatment measures and diagnostic tests were capped at a maximum of two per patient per day.

As claims databases, including the one used for this study, do not have an identifier for each unique office visit, office visits were broadly defined as the number of days the patient had one or more outpatient claims. Ophthalmologist visits were defined as office visits with the provider specialty listed as ophthalmologist/optometrist for the index diagnosis, or had an OCT examination and/or intravitreal injection. Because the database does not separate ophthalmologist from optometrist in the provider specialty field, our measure was an upper-bound number of ophthalmologist visit days.

\section{Outcome measures}

Anti-VEGF utilization was measured by the mean time to the first anti-VEGF treatment after initial diagnosis, the mean and distribution of the annual number of bevacizumab or ranibizumab injections, and the proportion of patients receiving ten or more injections (an approximation of monthly injections) annually. The statistical significance of the differences across cohort-years was compared using one-way analysis of variance. Claims databases typically do not provide a reliable identifier of which eye receives an intravitreal injection. This analysis therefore estimated the number of injections per patient, which is always equal to or greater than the number of injections per treated eye.

Laser or IVTA use in this population was evaluated by assessing the proportions of patients who received either or both therapies after the initial diagnosis, distinguishing between those who received laser or IVTA before the initiation of anti-VEGF therapy, and those who initiated laser or IVTA at the same time as or after their first anti-VEGF treatment.

To determine whether laser or ITVA use had an impact on anti-VEGF utilization, the mean annual numbers of anti-VEGF injections among those with or without laser or IVTA use were compared. The statistical significance of between-group differences was assessed using a twosided $t$-test assuming equal variances. To gauge the extent to which patients switched from anti-VEGF treatment to laser or IVTA, the proportion of patients who did not have a claim for additional anti-VEGF treatment after initiation of IVTA or laser but had at least two subsequent claims for an ophthalmologist visit for the index diagnosis was determined (ie, the upper-bound proportion of "potential switchers"). Patient-monitoring practices were measured by mean numbers of any office visits, ophthalmologist visits, and OCT and FA examinations during the 12 months after the index date.

\section{Results}

\section{Sample characteristics}

Of the 13,566, 7,727, and 19,814 patients diagnosed with BRVO, CRVO, and DME, respectively, 932, 644, and 2,765, respectively, met all inclusion and exclusion criteria (Figure 1). The vast majority of these patients received treatment with bevacizumab. The number of ranibizumab users in each diagnosis group (47, 33, and 32, respectively) was too low for meaningful analysis. Therefore, only results pertaining to patients treated with bevacizumab were reported. Among these patients, $51.0 \%$ of those with BRVO, $59.4 \%$ of those 
with CRVO, and 30.9\% of those with DME were 65 years of age or older, and approximately $50 \%$ of those in each diagnosis group were male (Table 1).

\section{Anti-VEGF utilization}

The mean time to first bevacizumab injection after the initial BRVO, CRVO, or DME diagnosis generally decreased over time, despite small fluctuations (Figure 2). For BRVO, the time to first injection declined from 68.5 days in the 2008 cohort to 45.7 days in the January-June 2011 cohort $(P=0.02)$. For CRVO, the time to first injection decreased from 54.5 days in the 2008 cohort to 35.7 days in the 2010 cohort, then increased slightly to 38.3 days in the January to June 2011 cohort; the differences across cohort-years were not significant $(P=0.09)$. For DME, the time to first injection declined significantly, from 85.2 days in the 2008 cohort to 57.5 days in the January-June 2011 cohort $(P<0.01)$, with a very slight increase in the full-year 2010 cohort.

The mean number of bevacizumab injections administered during the 12 months after the index date remained very low, with a slight increase over time (Figure 3A). The differences across the 2008, 2009, and 2010 cohorts were statistically significant for BRVO $(2.5,3.1$, and 3.3 , respectively; $P<0.01)$ and DME (2.2, 2.5, and 3.6, respectively; $P<0.01)$, but not for $\operatorname{CRVO}(3.1,3.1$, and 3.5 , respectively; $P=0.28$ ).
Further analysis indicated that most annual injections were received in the first 6 months of treatment (Figure 3B) for all three conditions.

In the most recent 2010 cohort, less than $6 \%$ of the patients (BRVO 3.3\%, CRVO 3.2\%, and DME 5.6\%) received ten or more injections in 12 months (approximation of monthly treatment) (Figure 4). About a third of patients in the BRVO (35.9\%), CRVO (38.8\%), and DME (31.2\%) diagnosis groups received three or more bevacizumab injections in the first 4 months of treatment (data not shown).

\section{Laser and/or IVTA use}

For the 2008-2010 cohorts, the use of additional laser and/or IVTA from the initial diagnosis to 12 months following the index date was most common in patients with DME $(58.5 \%$ $66.4 \%)$, followed by BRVO (36.6\%-53.8\%), and least common in those with CRVO (15.4\%-26.6\%) (Table 2). The percentage of patients who received laser or IVTA before the first bevacizumab injection (ie, in whom bevacizumab was not used as first-line therapy) decreased from the 2008 to the January-June 2011 cohorts for BRVO (16.2\%-6.7\%), CRVO (8.3\%-1.5\%), and DME (31.4\%-18.8\%). In the 2008, 2009, and 2010 cohorts, the proportion of patients who added or switched to laser or IVTA remained relatively stable for BRVO (30.4\%, 43.4\%, and 29.7\%, respectively) and DME

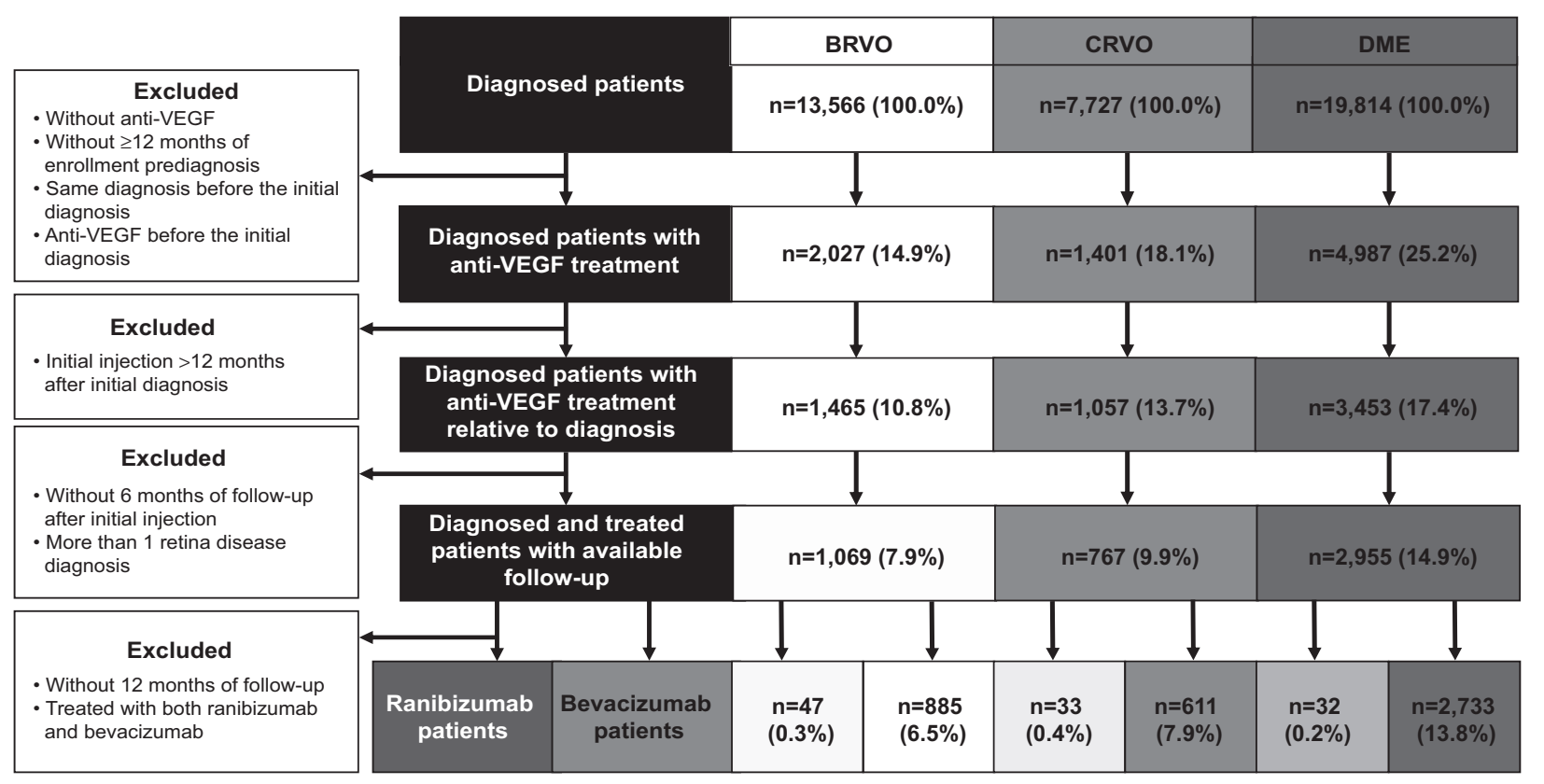

Figure I Patient flowchart.

Notes: Of the 13,566 BRVO-, 7,727 CRVO-, and 19,8I4 DME-diagnosed patients, 932, 644, and 2,765, respectively, met all inclusion and exclusion criteria, with most patients receiving bevacizumab. The low number of ranibizumab users in each group (47,33, and 32 , respectively) precluded a meaningful analysis for this agent. Abbreviations: BRVO, branch retinal vein occlusion; CRVO, central retinal vein occlusion; DME, diabetic macular edema. 
Table I Sample size and demographic characteristics of patients treated with bevacizumab or ranibizumab, by diagnosis group and cohort

\begin{tabular}{|c|c|c|c|c|c|c|}
\hline & \multicolumn{2}{|l|}{$\begin{array}{l}\text { BRVO } \\
(\mathrm{N}=932)\end{array}$} & \multicolumn{2}{|l|}{$\begin{array}{l}\text { CRVO } \\
(\mathrm{N}=644)\end{array}$} & \multicolumn{2}{|l|}{$\begin{array}{l}\text { DME } \\
(N=2,765)\end{array}$} \\
\hline & $\begin{array}{l}\text { Bevacizumab } \\
(\mathrm{n}=\mathbf{8 8 5})\end{array}$ & $\begin{array}{l}\text { Ranibizumab } \\
(n=47)\end{array}$ & $\begin{array}{l}\text { Bevacizumab } \\
(n=6 I I)\end{array}$ & $\begin{array}{l}\text { Ranibizumab } \\
(n=33)\end{array}$ & $\begin{array}{l}\text { Bevacizumab } \\
(n=2,733)\end{array}$ & $\begin{array}{l}\text { Ranibizumab } \\
(n=32)\end{array}$ \\
\hline \multicolumn{7}{|l|}{ Index cohort ${ }^{\mathrm{a}}$} \\
\hline 2008 & 148 & 3 & 120 & 2 & 338 & 4 \\
\hline 2009 & 221 & 0 & 172 & 0 & 560 & 6 \\
\hline 2010 & 306 & 21 & 188 & 9 & 1,009 & 13 \\
\hline 2011 (Jan-Jun) & 210 & 23 & $|3|$ & 22 & 826 & 9 \\
\hline Age $\geq 65$ years, $\%$ & 51.0 & 60.0 & 59.4 & 61.0 & 30.9 & 34.0 \\
\hline Male, \% & 49.6 & 40.0 & 54.9 & 39.0 & 54.5 & 53.0 \\
\hline
\end{tabular}

Notes: andex year was based on time of the first bevacizumab or ranibizumab injection. The 2008, 2009, and 2010 cohorts had 12 months of follow-up available, and the January-June 201 I cohort had 6 months of follow-up available.

Abbreviations: BRVO, branch retinal vein occlusion; CRVO, central retinal vein occlusion; DME, diabetic macular edema.

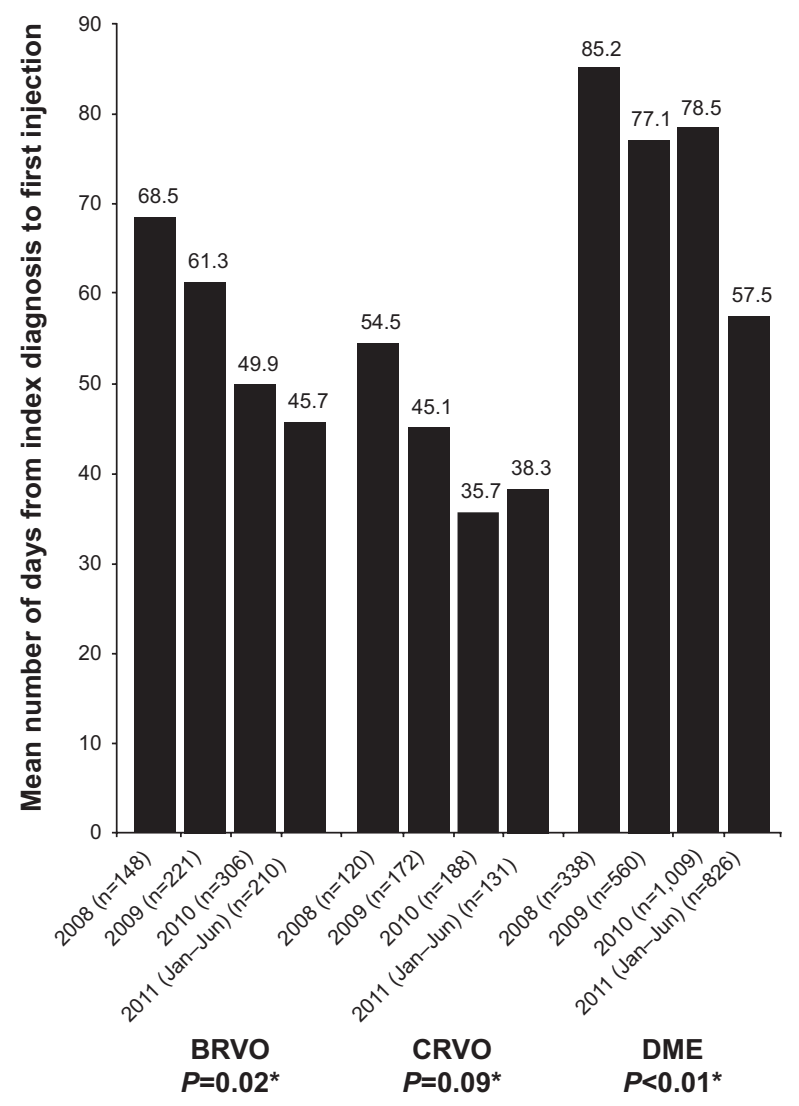

Figure 2 Mean days from index diagnosis to first bevacizumab injection, by diagnosis group and cohort.

Notes: *One-way analysis of variance comparing mean time across cohorts. Among those with a diagnosis of BRVO, there was a significant decrease in the mean days from initial diagnosis to first injection: 68.5 days in 2008, 6I.3 days in 2009, 49.9 days in 2010 , and 45.7 days in 2011 (January-June cohort, $P=0.02$ ). Although a decrease in time from initial diagnosis to first injection was observed in those with a diagnosis of CRVO (mean 54.5 days in 2008, 45.I days in 2009, 35.7 days in 2010, and 38.3 days in 2011 [January-June cohort]), the differences in mean time across the cohorts were not significant $(P=0.09)$. In the DME group, the mean time from initial diagnosis to first injections decreased significantly over time (from mean of 85.2 days in 2008, to 77.1 days in 2009, 78.5 days in 2010 , and 57.5 days in 201 I [January-June cohort]; $P<0.01$ ).

Abbreviations: BRVO, branch retinal vein occlusion; CRVO, central retinal vein occlusion; DME, diabetic macular edema.
( $29.6 \%, 35.9 \%$, and $31.1 \%$, respectively), but decreased for CRVO (from $18.3 \%$ to $11.7 \%$ ).

Of the patients treated with bevacizumab across the full-year 2008-2010 cohorts, a minority of patients (15.9\% BRVO, 5.6\% CRVO, and 15.8\% DME) were identified as potential switchers (ie, patients who discontinued bevacizumab use once laser or IVTA was initiated, but had at least two additional ophthalmologist visits) (Figure 5).

Across all cohorts, the annual number of bevacizumab injections was positively associated with laser use in BRVO (3.3 versus $2.9, P<0.03$ ) and with laser or IVTA use in DME (laser, 3.3 versus 2.7, $P<0.03$; IVTA, 3.3 versus 3.0, $P<0.05$ ), although the number of bevacizumab injections was low regardless of whether laser or IVTA was used (Table 3).

\section{Patient monitoring}

Across the 2008-2010 cohorts, the mean annual number of all doctor visits ranged between 16.6 and 17.4, 19.1 and 20.5, and 23.7 and 25.0 among patients diagnosed with BRVO, CRVO, and DME, respectively (Table 4). The number of ophthalmologist visits was generally low, but increased over time in the 2008, 2009, and 2010 cohorts for BRVO (5.1, 5.3, and 5.6, respectively) and DME (4.4, 4.8, and 5.3, respectively). The corresponding numbers for CRVO were 6.5, 5.8, and 5.9, respectively. During the same period, the mean annual numbers of OCT examinations ranged between 3.7 and 3.9 in patients with BRVO, 3.4 and 3.8 in those with CRVO, and 3.1 and 3.8 in those with DME; the mean annual numbers of FA examinations ranged between 0.9 and 1.2 for BRVO-, 0.7 and 1.0 for CRVO-, and 0.9 and 1.1 for DME-diagnosed patients. 
A
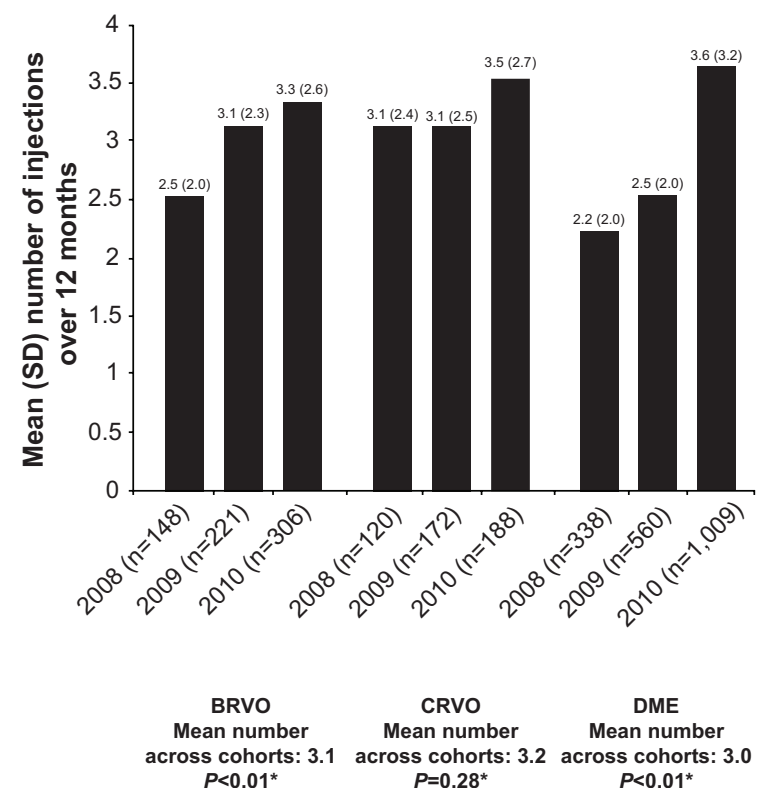

B

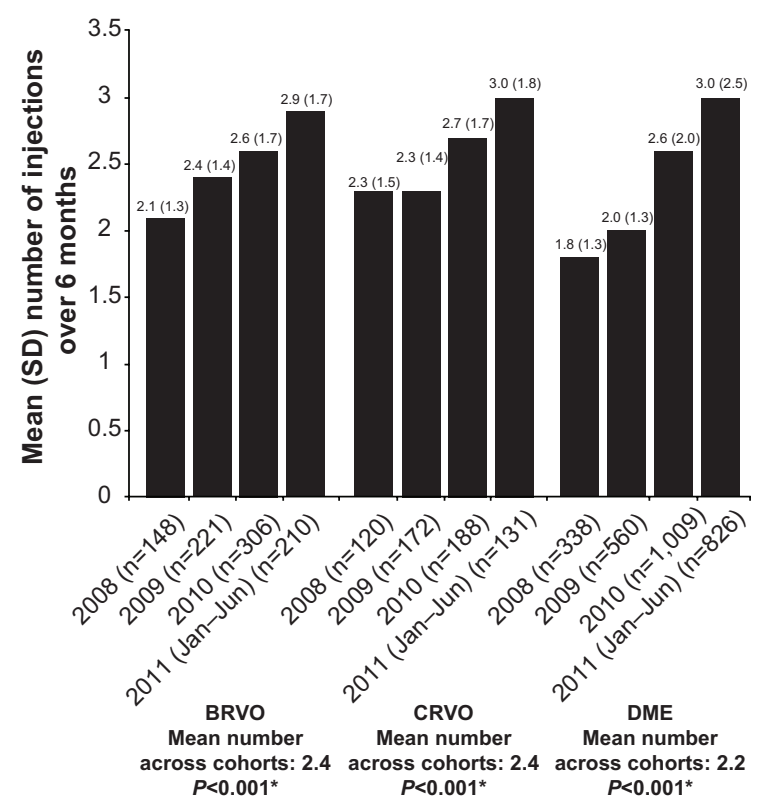

Figure 3 (A) Mean number (standard deviation [SD]) of bevacizumab injections over 12 months, by diagnosis group and cohort; (B) mean number (SD) of bevacizumab injections over 6 months, by diagnosis group and cohort.

Notes: *One-way analysis of variance comparing mean time across cohorts. In each diagnosis group, the mean number of injections administered over the I2-month period after the first injection (index date) increased, with mean differences across the cohorts being statistically significant in the BRVO and DME groups, but not in the CRVO group. Abbreviations: BRVO, branch retinal vein occlusion; CRVO, central retinal vein occlusion; DME, diabetic macular edema.

\section{Discussion}

This retrospective claims analysis of a large US insurance database identified over 2,000 patients newly diagnosed with BRVO, CRVO, or DME who were treated with bevacizumab or ranibizumab between January 2008 and December 2011.
The majority of patients were treated with bevacizumab. This is consistent with a higher overall use of bevacizumab in the retinal therapeutic area. ${ }^{27}$ It is also in large part due to ranibizumab not being reimbursed by health plans until after its approval for BRVO or CRVO in June 2010 and for DME in August 2012.

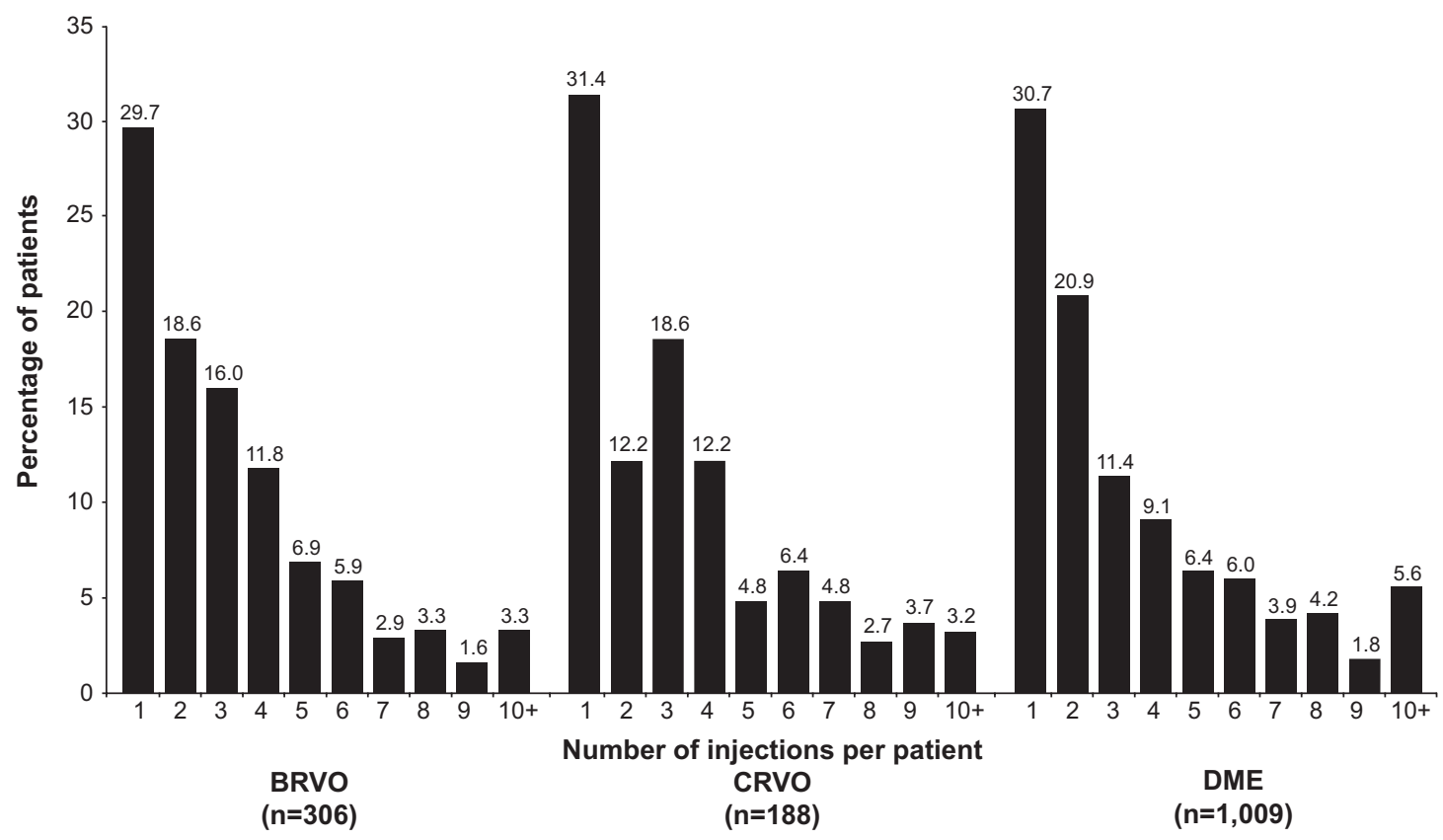

Figure 4 Distribution of the number of injections over 12 months in the 2010 cohort, by diagnosis group.

Notes: In analyses of the distribution of the number of injections in the 2010 cohort, small percentages of patients in each diagnosis group received $\leq 10$ injections during the 12 months after their index diagnosis.

Abbreviations: BRVO, branch retinal vein occlusion; CRVO, central retinal vein occlusion; DME, diabetic macular edema. 
Table 2 Proportions of bevacizumab-treated patients who received laser therapy or intravitreal triamcinolone, by diagnosis group and cohort

\begin{tabular}{|c|c|c|c|c|c|c|c|c|c|}
\hline \multirow{2}{*}{$\begin{array}{l}\text { Index cohort, } \\
\%\end{array}$} & \multicolumn{3}{|l|}{ BRVO } & \multicolumn{3}{|l|}{ CRVO } & \multicolumn{3}{|l|}{ DME } \\
\hline & All & $\begin{array}{l}\text { Before first } \\
\text { bevacizumab }^{\mathrm{a}}\end{array}$ & $\begin{array}{l}\text { After first } \\
\text { bevacizumab }^{\mathrm{b}}\end{array}$ & All & $\begin{array}{l}\text { Before first } \\
\text { bevacizumab }^{\mathrm{a}}\end{array}$ & $\begin{array}{l}\text { After first } \\
\text { bevacizumab }\end{array}$ & All & $\begin{array}{l}\text { Before first } \\
\text { bevacizumab }^{\mathrm{a}}\end{array}$ & $\begin{array}{l}\text { After first } \\
\text { bevacizumab }\end{array}$ \\
\hline $2008^{c}$ & $n=148$ & & & $n=120$ & & & $n=338$ & & \\
\hline Laser or IVTA & 46.6 & 16.2 & 30.4 & 26.6 & 8.3 & 18.3 & 61.0 & 31.4 & 29.6 \\
\hline Laser & 39.9 & 13.5 & 26.4 & 4.2 & 0 & 4.2 & 53.2 & 27.5 & 25.7 \\
\hline IVTA & 14.9 & 2.7 & 12.2 & 24.1 & 8.3 & 15.8 & 21.3 & 6.8 & 14.5 \\
\hline $2009^{c}$ & $n=221$ & & & $\mathrm{n}=172$ & & & $\mathrm{n}=560$ & & \\
\hline Laser or IVTA & 53.8 & 10.4 & 43.4 & 16.3 & 4.7 & 11.6 & 66.4 & 30.5 & 35.9 \\
\hline Laser & 46.2 & 7.7 & 38.5 & 4.1 & 1.2 & 2.9 & 59.3 & 27.5 & 31.8 \\
\hline IVTA & 14.0 & 3.6 & 10.4 & 13.4 & 3.5 & 9.9 & 21.3 & 5.9 & 15.4 \\
\hline $2010^{c}$ & $n=306$ & & & $\mathrm{n}=188$ & & & $n=1,009$ & & \\
\hline Laser or IVTA & 36.6 & 6.9 & 29.7 & 15.4 & 3.7 & 11.7 & 58.5 & 27.4 & 31.1 \\
\hline Laser & 32.7 & 5.6 & 27.1 & 2.1 & 0 & 2.1 & 53.1 & 25.2 & 27.9 \\
\hline IVTA & 7.2 & 2.0 & 5.2 & 11.7 & 3.7 & 8.0 & 15.3 & 4.2 & II.I \\
\hline 2011 Jan-Jun ${ }^{d}$ & $\mathrm{n}=210$ & & & $n=|3|$ & & & $\mathrm{n}=826$ & & \\
\hline Laser or IVTA & - & 6.7 & - & - & 1.5 & - & - & 18.8 & - \\
\hline Laser & - & 5.2 & - & - & 0 & - & - & 17.8 & - \\
\hline IVTA & - & 1.4 & - & - & 1.5 & - & - & 1.5 & - \\
\hline
\end{tabular}

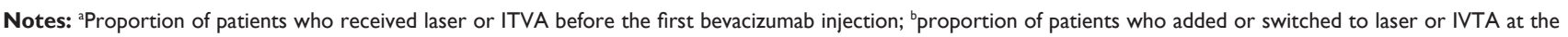
same time or after the first bevacizumab injection; 'these were indexed (time of the first anti-VEGF injection) from January I to December $3 \mathrm{I}$ of the calendar year and followed for 12 months; dhis cohort was indexed during January I to June 30, $201 \mathrm{I}$ and followed for 6 months. En dashes denote no data.

Abbreviations: BRVO, branch retinal vein occlusion; CRVO, central retinal vein occlusion; DME, diabetic macular edema; IVTA, intravitreal triamcinolone.

Our results revealed that an increasing number of patients were treated with anti-VEGF agents across BRVO, CRVO, and DME during the study period. In addition, the time between the initial diagnosis and anti-VEGF initiation decreased over time. However, the mean annual number of bevacizumab injections remained below four, despite a slight

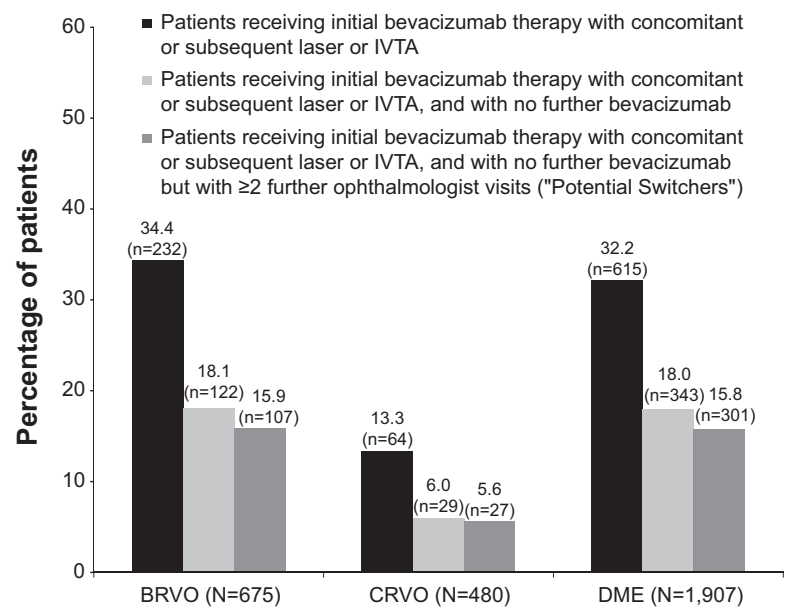

Figure 5 Use of laser and/or intravitreal triamcinolone relative to the timing of bevacizumab use during the first 12 months following the index date, by diagnosis group (2008-2010 cohorts).

Notes: In those with BRVO, CRVO, and DME, approximately $15.9 \%, 5.6 \%$, and $15.8 \%$, respectively, of the total diagnosis group were considered to have switched to either laser or IVTA treatment from bevacizumab treatment (ie, received laser or IVTA at the time of or after bevacizumab treatment, and then discontinued bevacizumab but continued to visit an ophthalmologist for at least two visits).

Abbreviations: BRVO, branch retinal vein occlusion; CRVO, central retinal vein occlusion; DME, diabetic macular edema; IVTA, intravitreal triamcinolone. increase during 2008-2011. In the most recent 2010 cohort that included patients followed through 2011 , less than $6 \%$ of the patients in each diagnosis group met the criteria for monthly injections, and less than $16 \%$ of patients in each diagnosis group met the criteria for monthly ophthalmologist visits (additional data not reported in tables/figures). These data are in sharp contrast to major ranibizumab Phase II and III pivotal trials, where the patients were monitored monthly and the mean annual numbers of injections were more than twofold greater: 8.4 in patients with BRVO (BRAVO trial), ${ }^{11}$ 8.8 in patients with CRVO (CRUISE trial),${ }^{14}$ and $7.0-11.0$ in patients with DME (RESTORE, ${ }^{13}$ Protocol $\mathrm{I},{ }^{17}$ and RISE/RIDE ${ }^{15}$ trials).

A variety of factors may have contributed to the very low numbers of monitoring visits and bevacizumab injections in clinical practice. Patients in a clinical practice may be inherently different from those enrolled in clinical trials. Our study period largely preceded the publication of the major clinical trials of monthly ranibizumab in BRVO and CRVO (the initial BRAVO ${ }^{28}$ and CRUISE $^{29}$ papers were published in mid-2010), and entirely preceded publication of clinical trials of monthly ranibizumab in DME (the RIDE/RISE paper ${ }^{15}$ was published in 2012). The lack of level 1 randomized controlled trial evidence likely contributed in large part to the wide variation in treatment schedules and overall suboptimal treatment frequencies. In addition, large bevacizumab trials conducted at the time, such as the 
Table 3 Mean number of bevacizumab injections in 12 months in the 2008-2010 cohorts by laser and/or intravitreal triamcinolone use and diagnosis group

\begin{tabular}{|c|c|c|}
\hline & $\begin{array}{l}\text { Mean number of bevacizumab } \\
\text { injections in } 12 \text { months }\end{array}$ & $\begin{array}{l}\text { P-value } \\
\text { (two-sided } t \text {-test) }\end{array}$ \\
\hline \multicolumn{3}{|l|}{ BRVO } \\
\hline With laser therapy/IVTA $(n=300)$ & 3.2 & 0.18 \\
\hline Without laser therapy/IVTA $(n=375)$ & 3.0 & \\
\hline With laser therapy $(n=261)$ & 3.3 & 0.03 \\
\hline Without laser therapy $(n=4 \mid 4)$ & 2.9 & \\
\hline With IVTA $(n=75)$ & 3.0 & 0.69 \\
\hline Without IVTA $(n=600)$ & 3.1 & \\
\hline \multicolumn{3}{|l|}{ CRVO } \\
\hline With laser therapy/IVTA $(n=89)$ & 3.4 & 0.57 \\
\hline Without laser therapy/IVTA $(n=39 I)$ & 3.2 & \\
\hline With laser therapy $(n=16)$ & 3.5 & 0.68 \\
\hline Without laser therapy $(n=464)$ & 3.2 & \\
\hline With IVTA $(n=74)$ & 3.3 & 0.73 \\
\hline Without IVTA $(n=406)$ & 3.2 & \\
\hline \multicolumn{3}{|l|}{ DME } \\
\hline With laser therapy/IVTA $(n=I, 168)$ & 3.3 & $<0.01$ \\
\hline Without laser therapy/IVTA therapy $(n=739)$ & 2.7 & \\
\hline With laser therapy $(n=I, 048)$ & 3.3 & $<0.01$ \\
\hline Without laser therapy $(n=859)$ & 2.7 & \\
\hline With IVTA (n=345) & 3.3 & 0.04 \\
\hline Without IVTA $(n=I, 562)$ & 3.0 & \\
\hline
\end{tabular}

Abbreviations: BRVO, branch retinal vein occlusion; CRVO, central retinal vein occlusion; DME, diabetic macular edema; IVTA, intravitreal triamcinolone.

BOLT study $^{30}$ and the DRCR.net Phase II bevacizumab study, ${ }^{31}$ used an every 6 -week administration schedule. This may have led physicians to believe that bevacizumab did not need to be administered monthly. Nonetheless, the mean annual number of injections in our sample fell short of an every 6-week administration schedule. Patients' lack of time and other resources in combination with the demand of managing other comorbidities may also prevent them from complying with more frequent ophthalmologist visits. For example, our results showed that on average, patients with BRVO and CRVO had about 16-20 doctor visits per year and those with DME visited doctors nearly twice every month. Consequently, physicians and/or patients may choose to prolong the time between injections. Finally, the lag time

Table 4 Mean numbers of office visits, ophthalmologist visits, and OCT and fluorescein angiography examinations in 12 months, by diagnosis group and cohort

\begin{tabular}{|c|c|c|c|c|}
\hline Index cohort ${ }^{a}$ & Office visits ${ }^{b}$ & Ophthalmologist visits ${ }^{c}$ & OCT examinations ${ }^{d}$ & $\begin{array}{l}\text { Fluorescein angiography } \\
\text { examinations }^{\mathrm{d}}\end{array}$ \\
\hline \multicolumn{5}{|l|}{ BRVO } \\
\hline $2008(n=\mid 48)$ & 16.6 & 5.1 & 3.7 & 1.2 \\
\hline $2009(n=22 I)$ & 17.4 & 5.3 & 3.9 & 1.1 \\
\hline $2010(n=306)$ & 17.3 & 5.6 & 3.9 & 0.9 \\
\hline \multicolumn{5}{|l|}{ CRVO } \\
\hline $2008(n=120)$ & 20.5 & 6.5 & 3.6 & 0.7 \\
\hline $2009(n=172)$ & 20.4 & 5.8 & 3.8 & 1.0 \\
\hline $2010(n=188)$ & 19.1 & 5.9 & 3.4 & 0.8 \\
\hline \multicolumn{5}{|l|}{ DME } \\
\hline $2008(n=338)$ & 23.7 & 4.4 & 3.1 & 0.9 \\
\hline $2009(n=560)$ & 24.8 & 4.8 & 3.8 & I.I \\
\hline $2010(n=1,009)$ & 25.0 & 5.3 & 3.6 & 1.0 \\
\hline
\end{tabular}

Notes: ${ }^{\mathrm{Y}}$ ear of first bevacizumab injection (2008, 2009, or 2010); ' defined as the number of days the patient had one or more outpatient claims; 'broadly defined as the number of days on which the patient had one or more outpatient claims for the index diagnosis with the provider specialty of "ophthalmologist/optometrist" or received an OCT examination and/or an intravitreal injection; 'capped at a maximum of two per patient per day.

Abbreviations: BRVO, branch retinal vein occlusion; CRVO, central retinal vein occlusion; DME, diabetic macular edema; OCT, optical coherence tomography. 
between randomized clinical trial publications and the incorporation of new treatment paradigms into practice may be another important contributing factor, as supported by the slow but increasing trend in numbers of injections over time in our study. This is similar to the trends noted in anti-VEGF treatment patterns in patients with nAMD. ${ }^{32}$

The large disparity in injection frequency, and more importantly in monitoring visit frequency, between the major clinical studies and routine clinical practice raises the possibility that patients' vision outcomes in the clinical setting may be substantially lower than those reported by the major clinical trials. This is supported by evidence from Phase II and III randomized controlled trials suggesting that in addition to monthly follow-up, more frequent injections generally result in higher absolute levels of vision improvement in DME and nAMD (Figure 6). ${ }^{12,13,15,17,20-22,30,33-35}$ However, few studies have examined the relationship between injection frequency and vision outcomes in BRVO, CRVO, or DME outside the clinical trial setting, although retrospective effectiveness studies of bevacizumab and ranibizumab in nAMD have found both injection frequency and vision improvement to be well below those reported in large published clinical trials. ${ }^{36-39}$

Our analysis indicated that the use of laser or IVTA is very common among bevacizumab-treated patients with BRVO and DME and less so in those with CRVO. The use of laser or IVTA as first-line therapy decreased substantially in patients with BRVO and CRVO and somewhat moderately in DME over time. In contrast, about $30 \%-43 \%$ of patients with BRVO and DME continued to add or switch to laser or IVTA either at the same time or after the initiation of bevacizumab injections. While many believe that the use of laser or IVTA could potentially extend the duration of anti-VEGF treatment, the use of laser in BRVO and the use of laser or IVTA in DME were positively associated with the number of bevacizumab injections in our study. This suggests that the use of concomitant and adjunctive treatment may be more indicative of the underlying disease severity or an overall generally more aggressive treatment strategy.

The strengths of this study include the use of a large national database composed of a diverse patient population. Our inclusion/exclusion criteria ensured high internal validity for the findings. Potential limitations include an insufficient sample of ranibizumab-treated patients during the study period. Because of an inability to distinguish between unilateral and bilateral treatment, per-patient numbers of injections and monitoring visits in this study are an upper bound for estimates of the numbers of injections and monitoring visits per

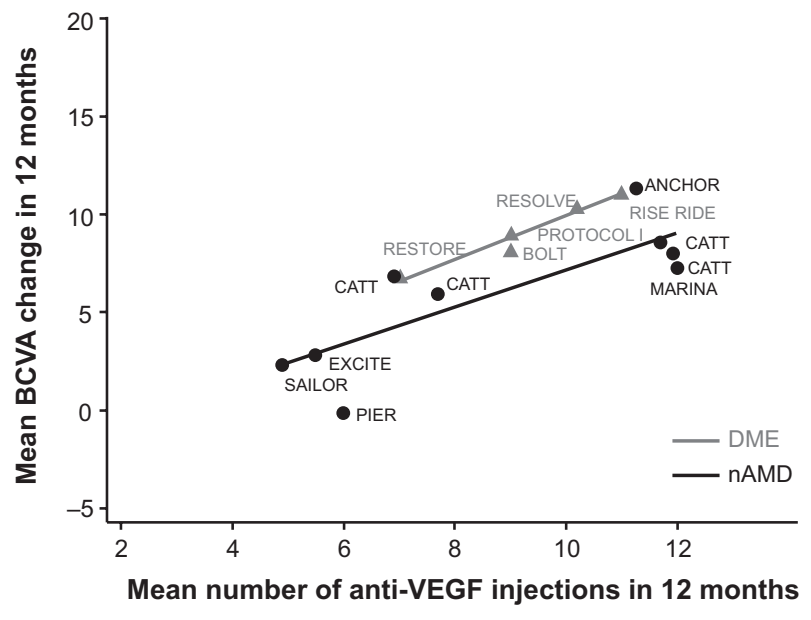

Figure 6 Correlations between number of bevacizumab and ranibizumab injections and mean ETDRS letters gained in 12 months in major published Phase II and III clinical trials in nAMD and DME.

Note: Evidence from major prospective clinical trials suggests a positive correlation between the administration frequency of bevacizumab or ranibizumab and visual improvement.

Abbreviations: BCVA, best-corrected visual acuity; DME, diabetic macular edema; ETDRS, Early Treatment Diabetic Retinopathy Study; nAMD, neovascular agerelated macular degeneration.

eye. In the absence of visual acuity or anatomical outcomes in claims databases, we were unable to identify potential outcome factors that may have influenced ongoing treatment decisions (eg, reduction or discontinuation of the treatments due to a lack or stabilization of visual acuity response, or achievement of acceptable vision outcomes with low injection frequencies). Nevertheless, the similarly low numbers of monitoring visits and OCT exams suggest that treatment outcomes may have only had limited impact on injection frequency. The stringent sample selection criteria were designed to maximize internal validity, but may limit the ability to generalize our findings to all patients with BRVO, CRVO, or DME. Finally, similar to other administrative databases, the IMS LifeLink health plan claims database lacks clinical details regarding severity of illness, and coding of diagnoses and procedures may be inaccurate or incomplete. The triple ICD-9 diagnostic codes for DME (ie, 362.07, a DME-specific code introduced in 2007, and the combination of 362.53 [cystoid macular edema] or 362.83 [retinal edema] with 250.xx [diabetes mellitus]), were derived from a validated algorithm that showed high sensitivity and specificity in identifying DME from pre-2007 claims data. ${ }^{25}$ These codes, which have been used in a previous claims analysis, ${ }^{26}$ represent relatively broad inclusion criteria for DME. However, in a related retrospective claims analysis using a different database, we found that the use of a more stringent DME-specific code (ie, 362.07, introduced first in 2007), which underestimated the prevalence of DME patients in the database, resulted in 
a similar mean annual number of injections. We therefore used the broad set of ICD-9 codes for a more complete characterization of the clinical DME population.

\section{Conclusion}

This large retrospective claims analysis provides the first comprehensive look at the utilization of anti-VEGF therapies in BRVO, CRVO, and DME in US clinical practice during the period leading up to publication of findings from major clinical trials of anti-VEGF agents in these indications. Our results show that the number of patients receiving bevacizumab for these conditions steadily increased. However, patients in clinical practice were monitored less frequently and received far fewer injections compared with patients in major clinical trials. Further research is necessary to confirm these findings in larger ranibizumab samples, to determine factors that may contribute to the observed low injection frequency, and to evaluate the visual outcomes associated with these reduced utilization patterns.

\section{Author contributions}

SK, YL, JB, NMH, AA, JC, and JWK were responsible for the design of the study, SK, YL, JB, NMH, AA, JC, and JWK for conduct of the study, collection, management, analysis, and interpretation of the data, and SK, YL, JB, $\mathrm{NMH}, \mathrm{AA}, \mathrm{JC}$, JWK for preparation, review, or approval of the manuscript.

\section{Acknowledgment}

Support for third-party writing assistance by Susan Ruffalo, PharmD of Med Write, Inc., was provided by Allergan, Inc.

\section{Disclosure}

This analysis was sponsored by Allergan, Inc., Irvine, CA. SK reports the following: consulting fees or honoraria-Alimera Sciences Inc., Allergan, Alcon, EyeTech, Genentech, Merge/OIS, Optos, Regeneron, and Thrombogenics; speakers bureaus - Alimera, Allergan, Genentech, Optos, Regeneron, and ThromboGenics; clinical research projects - Allergan, Genentech, Optos, and Regeneron; stock/stock options Merge/OIS. YL, JC, and JWK are employees of Allergan and hold equity and/or options in Allergan. JB is a full-time employee of IMS Health. NMH reports the following: consulting fees or honoraria - Genentech, Allergan, Regeneron, Sequenom, Inc., Alimera, and Notal Vision; board membership - Katalyst Surgical; speakers bureaus - Sequenom, Genentech, and Regeneron; clinical research projects - Notal Vision; stock/stock options - Katalyst Surgical. AA reports consulting fees or honoraria from Allergan. The authors declare no other conflicts of interest.

\section{References}

1. Romero-Aroca P. Managing diabetic macular edema: the leading cause of diabetes blindness. World J Diabetes. 2011;2(6):98-104.

2. Yau JW, Lee P, Wong TY, Best J, Jenkins A. Retinal vein occlusion: an approach to diagnosis, systemic risk factors and management. Intern Med J. 2008;38(12):904-910.

3. Turello M, Pasca S, Daminato R, et al. Retinal vein occlusion: evaluation of "classic" and "emerging" risk factors and treatment. J Thromb Thrombolysis. 2010;29(4):459-464.

4. Institute for Clinical and Economic Review (ICER). Technology Assessment Report: Anti-Vascular Endothelial Growth Factor Treatment for Diabetic Macular Edema. Boston: ICER; 2012. Available from: http:// www.cms.gov/Medicare/Coverage/DeterminationProcess/downloads/ id85TA.pdf. Accessed June 10, 2013.

5. Rogers S, McIntosh RL, Cheung N, et al. The prevalence of retinal vein occlusion: pooled data from population studies from the United States, Europe, Asia, and Australia. Ophthalmology. 2010;117(2): 313-319.

6. Yau JW, Rogers SL, Kawasaki R, et al. Global prevalence and major risk factors of diabetic retinopathy. Diabetes Care. 2012;35(3):556-564.

7. Aiello LP, Avery RL, Arrigg PG, et al. Vascular endothelial growth factor in ocular fluid of patients with diabetic retinopathy and other retinal disorders. N Engl J Med. 1994;331(22):1480-1487.

8. Andreoli CM, Miller JW. Anti-vascular endothelial growth factor therapy for ocular neovascular disease. Curr Opin Ophthalmol. 2007;18(6): 502-508.

9. Yoshimura T, Sonoda KH, Sugahara M, et al. Comprehensive analysis of inflammatory immune mediators in vitreoretinal diseases. PLoS One. 2009;4(12):e8158.

10. Sohn HJ, Han DH, Kim IT, et al. Changes in aqueous concentrations of various cytokines after intravitreal triamcinolone versus bevacizumab for diabetic macular edema. Am J Ophthalmol. 2011;152(4):686-694.

11. Brown DM, Campochiaro PA, Bhisitkul RB, et al. Sustained benefits from ranibizumab for macular edema following branch retinal vein occlusion: 12-month outcomes of a phase III study. Ophthalmology. 2011;118(8):1594-1602.

12. Massin P, Bandello F, Garweg JG, et al. Safety and efficacy of ranibizumab in diabetic macular edema (RESOLVE study): a 12-month, randomized, controlled, double-masked, multicenter phase II study. Diabetes Care. 2010;33(11):2399-2405.

13. Mitchell P, Bandello F, Schmidt-Erfurth U, et al. The RESTORE study: ranibizumab monotherapy or combined with laser versus laser monotherapy for diabetic macular edema. Ophthalmology. 2011;118(4): 615-625.

14. Campochiaro PA, Brown DM, Awh CC, et al. Sustained benefits from ranibizumab for macular edema following central retinal vein occlusion: twelve-month outcomes of a phase III study. Ophthalmology. 2011; 118(10):2041-2049.

15. Nguyen QD, Brown DM, Marcus DM, et al. Ranibizumab for diabetic macular edema: results from 2 phase III randomized trials: RISE and RIDE. Ophthalmology. 2012;119(4):789-801.

16. Heier JS, Campochiaro PA, Yau L, et al. Ranibizumab for macular edema due to retinal vein occlusions: long-term follow-up in the HORIZON trial. Ophthalmology. 2012;119(4):802-809.

17. Diabetic Retinopathy Clinical Research Network, Elman MJ, Aiello LP, et al. Randomized trial evaluating ranibizumab plus prompt or deferred laser or triamcinolone plus prompt laser for diabetic macular edema. Ophthalmology. 2010;117(6):1064-1077.

18. Elman MJ, Bressler NM, Qin H, et al. Expanded 2-year follow-up of ranibizumab plus prompt or deferred laser or triamcinolone plus prompt laser for diabetic macular edema. Ophthalmology. 2011;118(4): 609-614. 
19. Martin DF, Maguire MG, Fine SL, et al. Ranibizumab and bevacizumab for treatment of neovascular age-related macular degeneration: two-year results. Ophthalmology. 2012;119(7):1388-1398.

20. Brown DM, Kaiser PK, Michels M, et al. Ranibizumab versus verteporfin for neovascular age-related macular degeneration. $N$ Engl J Med. 2006;355(14):1432-1444.

21. Rosenfeld PJ, Brown DM, Heier JS, et al. Ranibizumab for neovascular age-related macular degeneration. $N$ Engl J Med. 2006;355(14): 1419-1431.

22. Martin DF, Maguire MG, Ying GS, et al. Ranibizumab and bevacizumab for neovascular age-related macular degeneration. $N$ Engl $J$ Med. 2011;364(20):1897-1908.

23. IVAN Study Investigators, Chakravarthy U, Harding SP, et al. Ranibizumab versus bevacizumab to treat neovascular age-related macular degeneration: one-year findings from the IVAN randomized trial. Ophthalmology. 2012;119(7):1399-1411.

24. Busbee BG, Ho AC, Brown DM, et al. Twelve-month efficacy and safety of $0.5 \mathrm{mg}$ or $2.0 \mathrm{mg}$ ranibizumab in patients with subfoveal neovascular age-related macular degeneration. Ophthalmology. 2013;120(5): 1046-1056.

25. Bearelly S, Mruthyunjaya P, Tzeng JP, et al. Identification of patients with diabetic macular edema from claims data: a validation study. Arch Ophthalmol. 2008;126(7):986-989.

26. Shea AM, Curtis LH, Hammill BG, et al. Resource use and costs associated with diabetic macular edema in elderly persons. Arch Ophthalmol. 2008;126(12):1748-1754.

27. Jumper JM, Mittra RA. ASRS 2012 Preferences and Trends Membership Survey. Paper presented at: 30th Annual Meeting of the American Society of Retina Specialists; August 25-29, 2012; Las Vegas, Nevada.

28. Campochiaro PA, Heier JS, Feiner L, et al. Ranibizumab for macular edema following branch retinal vein occlusion: six-month primary end point results of a phase III study. Ophthalmology. 2010;117(6): 1102-1112.

29. Brown DM, Campochiaro PA, Singh RP, et al. Ranibizumab for macular edema following central retinal vein occlusion: six-month primary end point results of a phase III study. Ophthalmology. 2010;117(6): 1124-1133.
30. Michaelides M, Kaines A, Hamilton RD, et al. A prospective randomized trial of intravitreal bevacizumab or laser therapy in the management of diabetic macular edema (BOLT study) 12-month data: report 2. Ophthalmology. 2010;117(6):1078-1086.

31. Diabetic Retinopathy Clinical Research Network; Scott IU, Edwards AR, et al. A phase II randomized clinical trial of intravitreal bevacizumab for diabetic macular edema. Ophthalmology. 2007;114(10):1860-1867.

32. Holekamp NM, Yeh WS, Chia Y, Kiss S, Almony A, Kowalski JW. Real-world utilization of intravitreal anti-vascular endothelial growth factor agents in common retinal diseases. Invest Ophthalmol Vis Sci. 2012;53(6):4179.

33. Boyer DS, Heier JS, Brown DM, Francom SF, Ianchulev T, Rubio RG. A Phase IIIb study to evaluate the safety of ranibizumab in subjects with neovascular age-related macular degeneration. Ophthalmology. 2009;116(9):1731-1739.

34. Schmidt-Erfurth U, Eldem B, Guymer R, et al. Efficacy and safety of monthly versus quarterly ranibizumab treatment in neovascular agerelated macular degeneration: the EXCITE study. Ophthalmology. 2011; 118(5):831-839.

35. Regillo CD, Brown DM, Abraham P, et al. Randomized, doublemasked, sham-controlled trial of ranibizumab for neovascular age-related macular degeneration: PIER study year 1. Am J Ophthalmol. 2008; 145(2):239-248.

36. Fong DS, Custis P, Howes J, Hsu JW. Intravitreal bevacizumab and ranibizumab for age-related macular degeneration: a multicenter, retrospective study. Ophthalmology. 2010;117(2):298-302.

37. Rotsos T, Patel PJ, Chen FK, Tufail A. Initial clinical experience of ranibizumab therapy for neovascular age-related macular degeneration. Clin Ophthalmol. 2010;4:1271-1275.

38. Bandukwala T, Muni RH, Schwartz C, Eng KT, Kertes PJ. Effectiveness of intravitreal ranibizumab for the treatment of neovascular age-related macular degeneration in a Canadian retina practice: a retrospective review. Can J Ophthalmol. 2010;45(6):590-595.

39. Bandello F, Holz FG, Gillies MC, et al. Safety, efficacy, treatment patterns of ranibizumab therapy for neovascular age-related macular degeneration: the LUMINOUS studies. Invest Ophthalmol Vis Sci. 2012 53(6):2031.
Clinical Ophthalmology

\section{Publish your work in this journal}

Clinical Ophthalmology is an international, peer-reviewed journal covering all subspecialties within ophthalmology. Key topics include: Optometry; Visual science; Pharmacology and drug therapy in eye diseases; Basic Sciences; Primary and Secondary eye care; Patient Safety and Quality of Care Improvements. This journal is indexed on Submit your manuscript here: http://www.dovepress.com/clinical-ophthalmology-journal

\section{Dovepress}

PubMed Central and CAS, and is the official journal of The Society of Clinical Ophthalmology (SCO). The manuscript management system is completely online and includes a very quick and fair peer-review system, which is all easy to use. Visit http://www.dovepress.com/ testimonials.php to read real quotes from published authors. 